Fecha de recepción: julio 2020

Fecha de aprobación: octubre 2020

Fecha publicación: enero 2021

\section{La mediación académica y la LIJ en México}

Dalina Flores Hilerio ${ }^{(1)}$

Resumen: En este trabajo se presenta un panorama actual de la LIJ en México en relación con la forma en que se ha introducido su estudio en el ámbito académico, y las prácticas editoriales de algunas empresas que han contribuido a su difusión y promoción, ya que en los últimos cinco años hemos observado una evolución trascendental en la percepción de algunos ambientes académicos hacia esta manifestación literaria. Abordamos este proceso desde las modificaciones en algunos programas académicos de las licenciaturas en Letras en México, en particular de la UANL, así como en las diversas publicaciones especializadas sobre la LIJ.

Palabras clave: Literatura Infantil y Juvenil (LIJ) - Crítica especializada - Educación superior - Mediación - Academia.

[Resúmenes en inglés y portugués en la página 226]

(1) Doctora en Filosofía con acentuación en Estudios de la Cultura y maestra en Lengua y Literatura Hispánicas por la Universidad Autónoma de Nuevo León (UANL). Profesora e investigadora en la Facultad de Filosofía y Letras de la UANL y en el Tecnológico de Monterrey. Obtuvo el Premio Nacional de Fomento a la Lectura "México lee 2010". Dirige el programa de promoción de la literatura Biblionautas desde 2001. Ha impartido cursos y conferencias sobre LIJ en México y otros países como Chile, Cuba y Brasil. Es editora de la revista Navegantes, sobre literatura infantil y juvenil, publicada de forma impresa por la Editorial Universitaria de la UANL.

La segunda mitad del siglo XX fue crucial para renovar la tradición de la Literatura Infantil y, de manera muy embrionaria, empezó a reconocerse el público adolescente y juvenil como objetivo de las casas editoriales. A diferencia de la tradición literaria "para adultos", la aceptación académica de lo que actualmente se conoce como LIJ (Literatura Infantil y Juvenil) ha sido difícil, paulatina y, en muchos espacios, todavía irrelevante o nula.

En gran medida, esta tendencia podría relacionarse con el prejuicio que tiene la tradición crítica respecto a la mirada del lector infantil, al considerar que una literatura escrita para niños carecería de los principios literarios fundamentales que, según Croce (1979), son 
tan complejos e inalcanzables para la mente infantil. Una de las principales razones para concebirlo de esta manera es porque la infancia se relaciona directamente con el juego y el gozo, y ambas conductas suelen penalizarse por el comportamiento adulto. Sin embargo, esta percepción se ha ido modificando de una manera precisa en la medida en que el corpus literario escrito para niños en México se ha profesionalizado, y también ofrece una serie de recursos estéticos y retóricos tan complejos como los que se ubican dentro de la literatura canónica o canonizada (para adultos).

En la conferencia Algunas características y funciones de la literatura infantil y juvenil mexicana contemporánea, que presenté durante el Colóquio Internacional de Estudios Literários, en la Universidad de Mato Grosso (2014) en Brasil, expuse las condiciones de la LIJ contemporánea en México y señalé, entonces, que a la LIJ le hacía falta una mirada más profunda desde la crítica académica, pues si bien la función de los mediadores y otros promotores de lectura estaba aportando nuevas prácticas y dinámicas para acercar a los niños y jóvenes a la lectura, los círculos académicos aún se resistían no sólo a su análisis, sino a considerarla dentro del corpus literario. A seis años de esa conferencia, actualmente hemos visto una evolución muy interesante en torno al fenómeno de la LIJ en México, debido a la función tan relevante que han desarrollado algunos críticos formados profesionalmente en los estudios literarios; o bien, debido a otros elementos relacionados con la tecnología, como la tarea que están realizando algunos escritores reconocidos dentro de la "alta literatura", como Alberto Chimal, en la plataforma de Youtube donde, además de recomendar obras, autores y compartir estrategias en la construcción literaria, también realiza "video-ensayos", es decir, analiza y reflexiona, con herramientas teóricas, algunas obras, a través de argumentos rigurosos respecto a la tradición.

Asimismo, es trascendental la tarea de algunos mediadores que han dado divulgación profesional al análisis crítico de la LIJ desde plataformas digitales muy democráticas, como las bitácoras personales (blogs) con un enfoque académico, sin perder de vista la divulgación. La cada vez más nutrida participación de investigadores sobre LIJ en congresos especializados y la creciente publicación de artículos en espacios académicos, como la revista LIJ Ibero. Revista de literatura infantil y juvenil contemporánea, también ha contribuido a darle espacio y visibilidad a este enfoque y ha abierto el diálogo entre las diferentes rutas críticas, de la misma manera en que algunas editoriales interesadas en la LIJ (El Naranjo, Tres Abejas, CIDCLI, Castillo, Tecolote, etcétera) cada vez son más críticas con la curación de sus colecciones y su trabajo artístico editorial, en gran medida por las aproximaciones que de sus productos ha hecho la crítica formal.

Un primer objetivo de este trabajo es definir algunos aspectos sobre la Literatura Infantil y Juvenil para caracterizarla y evidenciar cómo ha cambiado la percepción de algunas academias al respecto, así como ciertos rasgos que han contribuido a que se modifique sustancialmente su tratamiento dentro de estos círculos, pues la mediación de la lectura en nuestro país se ha asociado más con el desarrollo de habilidades sociales y afectivas en los niños, que con las cognoscitivas o intelectuales y, quizás por eso, desde el ámbito académico, se aborda principalmente como un elemento importante en el aprendizaje socioemocional y el desarrollo axiológico en la primera infancia.

De acuerdo con Francisco Hinojosa, considerado como el padre de la Literatura Infantil mexicana contemporánea, luego del éxito editorial que logró con La peor señora del mundo 
(1992), en nuestro país se publican muchos libros para niños, dentro de los que destacan los informativos, pedagógicos, incluso moralizadores o de entretenimiento (para pintar, recortar, etcétera); sin embargo, aún es poca la Literatura Infantil. Es decir, sigue siendo reducida la publicación de textos de corte literario cuyo fin no sea eferente. Hace algunas décadas, la ausencia de una postura crítica sistemática provocaba que todo libro escrito para niños se considerara como cualquier otro libro escolar, educativo o moralizante. Y, justo por eso, dentro del ámbito académico no se consideraba seriamente su estudio.

La esencia de lo literario, no obstante, es un asunto que sigue tratando de dilucidarse a través de diferentes disciplinas, ya que su componente estético ofrece un terreno muy resbaladizo para edificarle un perfil concreto. La Literatura, desde la Estética de la recepción, significa una gama muy amplia de elecciones, aspiraciones y valores con los cuales el individuo debe rearmar su filosofía personal, a partir de su propio proceso de lectura (Iser, 1987). La infinita diversidad del arte literario, sumada a la complejidad de la personalidad o a los antecedentes de cada ser humano, justifican la insistencia en la peculiar naturaleza de la experiencia literaria y en la necesidad de preparar al lector para que se involucre en su propio proceso de evocar (co-construir) la esencia literaria del texto.

Alfonso Reyes asegura en El Deslinde (1963) que el texto artístico es insustituible, a diferencia de la lectura eferente (utilitaria) que puede ser parafraseada y remplazable. Un poema no puede parafrasearse sin que cambie su significación; además, nadie puede leer un poema por nosotros, ya que el lector debe tener una experiencia a partir de él. Debe "vivir a través" de lo que está siendo creado durante la lectura (Rosenblatt, 2002, p. 24). Esta transacción remueve tanto los aspectos referenciales como los afectivos de la conciencia, y la atención que se le concede a cada uno determina dónde se ubica el texto respecto a un continuum, que va desde lo predominantemente eferente a lo predominantemente estético. A partir de esta mezcla de sensaciones, sentimientos, imágenes e ideas se estructura la experiencia que constituye la narración, el poema o la obra de teatro (Rosenblatt, 2002, p. 60). Algunas definiciones de la experiencia estética suelen postular que el arte brinda una satisfacción más completa de los impulsos y necesidades humanas que la vida cotidiana, con sus frustraciones e irrelevancias; pero esta compleja experiencia no depende de la obra misma, sino de las capacidades y disposiciones del lector, es decir, de sus competencias lectoras o, como las nombra Mendoza Fillola, sus competencias lecto-literarias (2004, p. 46). Al respecto, Rosenblatt (2002) señala que no sólo se debe leer Literatura, sino también aprender a leer literariamente. Esto quiere decir que el acto de leer Literatura es una experiencia vital -una forma de vivir vicariamente vidas y emociones ajenas y acercarse a las propias- $y$, por tanto, de enfrentar dilemas profundos de la existencia; por eso podríamos considerar que no todos los libros escritos para niños detonan esta experiencia.

El proceso recíproco que surge al estar leyendo (los ojos recorren una serie de signos y éstos remueven huellas de las experiencias pasadas del lector) es una acción intrínseca entre el lector y los signos: el sentido no está ni en el texto solo, ni en la mente del lector, sino en la mezcla continua, recurrente, de ambos, lo cual conduce a este último a la activación de muchas diferentes líneas de pensamiento. A esta particularidad del acto de leer Rosenblatt la llama "teoría transaccional" (2002, p. 14). Para Croce (1997), este proceso no puede generarse en la mente infantil porque, en primer lugar, se necesita un amplio bagaje de experiencias para poder conectarlas con el texto literario; sin embargo, la Literatura In- 
fantil y Juvenil contemporánea, desde la corriente neosubversiva, que ha analizado Laura Guerrero Guadarrama (2012), propone alternativas lúdicas y complejas a los jóvenes y niños lectores; es decir, la configuración del texto literario para estos públicos plantea, en mayor o menor grado, un reto para la interpretación, la reflexión y el diálogo constructivo a partir del planteamiento estético de los textos.

La Literatura Infantil se involucra en la vida y las necesidades humanas, y las sirve, a través del ejercicio del oficio literario para crear obras de atractivo estético. Canónicamente, se ha señalado que el texto literario implica la existencia de dos entidades inseparables: la forma, regida por patrones estéticos; y el fondo o contenido. Para Rosenblatt, la literariedad de un texto radica en su alejamiento de la referencialidad (2002, p. 57), por lo que lectores, de cualquier edad, lejos de "traducir" el código a uno más accesible, experimentan y juegan con las diversas percepciones que la literatura les provoca. Lo literario se define, entonces, a partir del proceso de lectura, no necesariamente por el texto mismo; es decir, su cualidad artística tiene que ver con el nivel afectivo y evocativo del texto, a través del grado de estimulación (apelación) que causa en el receptor, y no con los parámetros de la clasificación de diferentes escuelas o tendencias literarias.

Las actividades cognitivas realizadas en el proceso de lectura permiten que el lector capte la potencialidad funcional y expresiva del sistema de la lengua en el discurso escrito, además de ofrecerle muestras de las diversas modalidades de expresividad que se realizan a través de la lengua, con lo que se puede poner en relieve lo particular de la literatura, sus funciones sociales (transmisión de modelos y valores culturales) y las funciones formativas del individuo (interacción con el texto, construcción de significados, valoración e interpretación, etc.) (Mendoza-Fillola, 2004, p. 109). Por lo tanto, es de vital importancia que las academias asuman su responsabilidad en cuanto a la formación de lectores, al construir puentes sólidos para apuntalar la competencia lecto-literaria, a partir del análisis crítico del corpus que la LIJ ofrece, para que las editoriales, y mediadores en general, también se integren al proceso de reflexión crítica y a la selección de sus materiales de trabajo. El texto literario es una entidad estética que está en el terreno del arte. En Filosofía de la vida artística (1988), Samuel Ramos señala que, aunque la variedad de las manifestaciones artísticas es tan diversa y muchas veces contradice cualquier tesis estética, sí es posible identificar en ellas una lógica de la representación sensible. Para él, así como la perfección del conocimiento racional es la verdad, la perfección de la representación sensible es la belleza (1988, p. 12); sin embargo, la concepción de lo bello no se limita a la repetición de los paradigmas socialmente establecidos y aceptados. Como producto de la actividad espiritual del ser, el arte debe considerarse en el ámbito integral de la cultura, a partir del sujeto artístico (artista, espectador, crítico) y el objeto creado (la obra de arte), y de cómo éstos interactúan en su contexto. Es decir, la valoración artística también es fundamental para legitimar y reconocer la esencia literaria de los textos publicados, en el caso que nos atañe, para niños y jóvenes. Para lograr un acercamiento más amplio y certero a la Literatura Infantil y Juvenil, necesitamos generar el interés de lectores legos, o con poca experiencia, a través de actividades lúdicas y de esparcimiento; pero la manera más eficaz para profundizar en los problemas que presenta la LIJ, en su producción, circulación y recepción, es mediante una observación sistematizada y un diálogo vasto en contextos académicos que sin duda redundará en la creación de nuevas narrativas, discursos y acercamientos teóricos a la LIJ. 
De hecho, la crítica literaria sobre LIJ nos propone una serie de dificultades metodológicas y estructurales pues la función de toda crítica, según Terry Eagleton (1999), es valorar la producción artística de los autores y su pertinencia en el campo cultural e implica la evaluación del hecho literario en el campo político, por lo que el discurso se convierte en una práctica que impacta directamente en la sociedad, para modificarla o legitimar los valores vigentes; es decir, la producción del texto artístico y su valoración (a través de la crítica) es fundamental para la configuración de la cultura.

Aunado a esta complejidad, cuando escribimos crítica académica sobre libros dirigidos a un público infantil, adolescente y joven, los receptores son otros especialistas o profesionales involucrados en el ejercicio de la mediación de la lectura y la escritura; es decir, el público lector meta de nuestros trabajos críticos no son los lectores ideales del texto literario infantil o juvenil. Sin embargo, establecemos rutas críticas y ponderaciones para que otros especialistas se conviertan en puente que conecte la valoración de la Literatura Infantil con los lectores niños y jóvenes. En este sentido, la labor del crítico de LIJ tendrá que dirigirse a un público especializado, sin perder de vista que nuestro interés también radica en promocionar la lectura literaria entre niños y jóvenes. Así pues, coincidimos con González Gil (1979) en la necesidad de una crítica formal sobre LIJ donde se vincule su relación con la Didáctica de la literatura, así como con la Creación literaria para niños:

[necesitamos] una crítica al servicio de esta Literatura. Una crítica que ofrezca puntos de referencia y posibilidades de discernimiento a niños y jóvenes; una crítica al servicio del público y de la creación misma, estimulando a los autores y potenciando la capacidad de creación de los niños (1979, p. 274).

Para entender la función de la crítica hacia la Literatura Infantil y Juvenil es necesario desatar el concepto, pues los perfiles de niños y jóvenes son muy disímiles; incluso, aunque tampoco es una idea general, hay mayor similitud entre los distintos grupos de adultos, que entre los que configuran la población de no-adultos. La mayoría de los niños lectores, por ejemplo, inician su recorrido por el mundo de los libros en un marco lúdico (escolar o extraescolar) y acompañados. Los lectores jóvenes, por su parte, se distinguen por ser autónomos y, en su mayoría, empiezan a leer desde pequeños, aunque seguir leyendo como jóvenes les confiera un perfil de adulto lector, según la Encuesta Nacional de Lectura realizada en 2015 en México.

\section{Caracterización de la Literatura Infantil}

A pesar de que, hasta la primera mitad del siglo XX, se consideraba que lo único que podía ser literario era la escritura de textos para adultos, actualmente se reconoce que la literatura forma parte de la vida del niño desde temprana edad y es un estímulo vital para su pensamiento, por lo que algunos autores contemporáneos han enfocado su atención en la escritura para niños, de manera que se ha llegado a profesionalizar. Es primordial entonces que la crítica formal vaya por el mismo camino. 
En Europa y Estados Unidos los anaqueles se clasifican por género y según la edad de los lectores. En otros países como Alemania y Suecia, el libro infantil ocupa un lugar imprescindible en el proceso de la formación integral del infante. Incluso en México, según Francisco Hinojosa, el segundo lugar en ventas es el género infantil, después de los de superación personal (conferencia 2010, Facultad de Filosofía y Letras, UANL). Esto quiere decir que los textos de Literatura infantil persiguen un propósito particular que es a la vez formativo, informativo, pero, sobre todo: recreativo; esta última capacidad impulsa el pensamiento crítico y la emoción estética, a través de la experimentación lúdica del mundo. Y justo por esta potencialidad es que la crítica literaria debería dirigir su mirada con mayor rigor sobre estos productos culturales para encargarse de su exégesis y valoración.

La Literatura Infantil contemporánea hace propuestas literarias y plásticas que, más allá del sentido literal, pretenden erigirse como obras artísticas universales. Así como la música, la danza y la pintura contribuyen a desarrollar otras áreas de la capacidad intelectual de los chicos en formación, la Literatura les permite, además de enriquecer su acervo lingüístico, experimentar la vida desde una perspectiva estética y crítica y con ello trascender el mundo rapaz de lo material. La estética de la palabra es una posibilidad para el juego, y esta práctica renueva cualquier rutina. Si a un pequeño se le priva de esta posibilidad, se le está coartando su libertad espiritual.

De acuerdo con Sartre (1991), el arte no pierde nada con el compromiso y, al contrario, lo complementa; en el ámbito de la Literatura Infantil es posible observar que las exigencias siempre nuevas de lo social imponen al artista la necesidad de reencontrar un lenguaje nuevo o técnicas nuevas. Si ya no escribimos como en el siglo XVII es porque ese lenguaje dejó de ser operante para proyectar la realidad contemporánea. De esta manera, la mirada crítica tendría que abonar al cuestionamiento de valores y recursos anacrónicos en la Literatura Infantil y Juvenil, para que también sea, como reconoce Samuel Ramos (1988), una actividad de la creación literaria.

La postura sociológica respecto al Arte parece pesimista y tajante. La Literatura Infantil contemporánea, como cualquier texto circunscrito al universo textual de una cultura, posee una ideología, o manifiesta subrepticiamente los usos de una cultura; sin embargo, su apertura hacia lo lúdico permite que el niño explore y se cuestione sobre el universo que lo rodea y que está integrado al texto mismo.

A pesar de que la Literatura Infantil contemporánea refleja claramente valores concernientes a la realidad social, no pretende una "reproducción" burguesa de valores superficiales, al contrario, intenta hacer de los niños seres críticos, intuitivos y creativos, capaces de "sentir" y asimilar el texto desde una perspectiva artística.

Es necesario enfatizar esta función de la prosa en la Literatura Infantil pues, como hemos dicho, mientras más preceptivo es un texto, más capacidad de rechazo provoca en los niños. Otro tanto se aplica en cuanto a la "didáctica" de la lectura y la Literatura: sería necio tratar de repetir los esquemas educativos que dieron resultados poco alentadores en el siglo pasado. El arte, al igual que la tecnología, día a día participa en revoluciones. La Literatura Infantil contemporánea tiene objetivos específicos que tratan de cubrir las necesidades de los niños del siglo XXI, entre las que se prioriza el derecho a la fantasía y la imaginación, y se reconoce su inteligencia y su participación como coautores del texto (participación activa a través de la interpretación y la reflexión). Y aunque todavía no 
podemos considerar que la literatura Infantil sea una práctica legitimada totalmente por el mundo académico intelectual, ya son muchos los espacios universitarios e institucionales en los que se reconoce su importancia y se integra a las conversaciones académicas formales.

En este sentido, los escritores de Literatura Infantil contemporánea están planteando textos subversivos que obedecen a la valoración crítica de los (aún pocos) académicos e investigadores que han empezado a plantear rutas críticas para abordar la LIJ, y se han comprometido con un público cada vez mayor y más exigente que ejerce, en la medida de sus requerimientos, una crítica activa y profunda. Desde que hemos permitido a los niños asumir el lugar que les corresponde en el contexto sociocultural, son ellos quienes ejercen una crítica que exige al escritor el compromiso y la sensibilidad de acercarse al mundo infantil para interpretarlo desde su interior como si fuera un niño más.

La teoría y la crítica se han preocupado entonces por dar una nueva clasificación, ya no temática, sino estructural, a la elaboración del discurso literario para niños. Propp, en Morfología del cuento (ruso) (2006) ubica diferentes rubros según la manera en que están articulados los relatos, donde prioriza la estructura de la trama (pp. 52-56) y por eso el cuento ha sido empleado en la educación formal e informal (aunque no siempre se ha valorado como instrumento pedagógico). Sin dejar de reconocer la importancia del cuento tradicional en el desarrollo de la Literatura, y en particular en la tradición de la Literatura Infantil en México, impulsar el acercamiento de los niños a este tipo de historias resulta limitado y anacrónico, ya que los asuntos que tratan fueron significativos para una época ajena a las necesidades del mundo actual.

Por otro lado, la mayor objeción a la "implementación" de la lectura de cuentos infantiles clásicos en las aulas, o en la vida cotidiana, es su alto contenido machista que refuerza actitudes pasivas que llegan incluso a lo peyorativo en los personajes femeninos, y violentas y agresivas en los masculinos. Los cuentos clásicos infantiles suelen repetir ese esquema. Son interesantes como un tipo de discurso narrativo y como producto histórico que refleja usos y costumbres; sin embargo, los pequeños lectores de hoy necesitan propuestas más dinámicas, interdisciplinarias y que sean cercanas a su experiencia personal.

La Literatura Infantil contemporánea es una opción que permite a los lectores actuales trascender los paradigmas del cuento clásico ya que ofrece propuestas diversas, desde lo más realista hasta lo menos figurativo, aborda todo tipo de temas, y estos son actuales y cercanos a su contexto (Caperucita en Manhattan (1990), Mi amigo el pintor (1986), El libro de la negación (2014), Ella trae la lluvia (2016)), cuyos autores los manejan sin eufemismos ni condescendencia, pero sí con creatividad y desafío para los niños y jóvenes del siglo XXI.

La descripción del canon literario ha sido una tarea sumamente compleja desde que el estructuralismo empezó a forjar definiciones (aún antes); sin embargo, el concepto de Literatura Infantil al que se ha llegado para los fines de este trabajo se fundamenta en la idea tradicional de "Literatura" (que privilegia sus particularidades connotativas, estéticas, expresivas y críticas) y las propuestas visuales, que funcionan como un intertexto en la experiencia literaria (inicial) del público infantil. De esta manera, la Literatura Infantil contemporánea concatena la propuesta lingüístico-textual de los autores, así como la visual de los ilustradores, para despertar el interés del niño y multiplicar sus interpretaciones, por 
tratarse de códigos abiertos (no lineales ni literales). De esta manera, la Literatura Infantil contemporánea reconoce al lector como un ser pensante, inteligente y capaz de emitir juicios; y busca que éste establezca un diálogo consigo mismo y con el texto, a propósito de las ideas que le plantea de forma explícita e implícita; es decir, este proceso detona un diálogo constante y permanente (Gadamer, 1987) entre el lector y la obra literaria, dentro de la que va generando inferencias al unir la información de su contexto y las conclusiones derivadas de su experiencia literaria.

A partir de las ideas anteriores, consideramos válidas dos categorías textuales como representativas de las propuestas de Literatura Infantil contemporánea, independientemente de su connotación subversiva: 1. El libro álbum y los libros ilustrados que proponen un juego abierto con el lector al considerar las imágenes como un recurso intertextual, no siempre en correspondencia literal al texto escrito; y 2. La Literatura de escritores profesionales, ya sea por su experiencia en el campo literario canonizado o porque se han formado académicamente como creadores de Literatura Infantil. La primera de ellas encierra un contenido muy atractivo para los niños ya que, sin importar el estilo artístico del ilustrador, en la actualidad, los diseños editoriales retan al lector para que active sus capacidades cognitivas, en vez de ser una mera "ilustración" literal del texto, como suele aparecen en la "literatura" infantil comercial.

Es preciso señalar que al hablar de álbumes infantiles ilustrados no debemos considerar cualquier publicación comercial como parte de esta categoría. Arizpe y Styles consideran que un álbum ilustrado es "... texto, ilustraciones, diseño total [pero también] un documento social, cultural, histórico y, antes que nada, una experiencia para los niños" (2004, p. 43); el punto de interdependencia, sin embargo, no es correlativo, sino complementario. A diferencia de los álbumes ilustrados que forman parte de la Literatura Infantil contemporánea, los textos infantiles comerciales no se preocupan por generar retos al lector; su función principal es vender y facilitar la tarea del lector, ilustrando "cabalmente" las historias; para ello publican textos sin complejidades lingüísticas ni visuales (los libros infantiles de Disney, por ejemplo, cuyas imágenes son sólo una manera alternativa de contar la misma historia). Esto no quiere decir que carezcan del componente recreativo, pero no son la mejor alternativa para despertar el pensamiento crítico ni la emoción estética en los lectores. La Literatura Infantil contemporánea, por lo tanto, promueve la ejercitación profunda de la lectura activa, donde el lector va construyendo el significado a medida en que actualiza la lectura textual. Para Iser esta acción es el fundamento sobre el que se construye una teoría de comunicación literaria (1987, p. 9); es decir, a partir de la relación dialéctica entre el texto, el lector y su interacción. A través de la integración del código visual en el texto artístico y literario, el niño percibe emocional y cognitivamente la relación entre imágenes y palabras. Según Mendoza Fillola este proceso ayuda a refinar y desarrollar las competencias lecto-literarias al permitir que se integre la experiencia personal en la interpretación y viceversa (2004, p. 39).

Los álbumes ilustrados, de acuerdo con Arizpe y Styles, abren a los niños la puerta de entrada al mundo de la Literatura, ya que presentan los primeros esbozos de los diferentes tipos de narración, que sólo se reconocen cuando se tiene acceso a una amplia variedad de textos (2004, p. 58); y al mismo tiempo, permiten que este acercamiento se realice más temprano, ya que los niños empiezan a leer imágenes antes que palabras. 
El texto visual ayuda a que los pequeños integren el mundo a su experiencia a través de sus sentidos (Arizpe y Styles, 2004). Sin embargo, la Literatura Infantil contemporánea no se limita a ser una mera propuesta plástica; al integrar el texto escrito como un mediador entre los procesos internos del pensamiento (Vygotsky, 1995) también abre una ruta para llegar al conocimiento y a la socialización.

Una de las características más importantes de la Literatura Infantil contemporánea, sea ilustrada o no, es la relevancia del manejo de la lengua como materialidad, debido a sus recursos estilísticos, retóricos y ficcionales. El autor que escribe para niños está comprometido con la visión infantil, lo cual no quiere decir que utilice textos condescendientes; al contrario, pretende un acercamiento íntimo a estos lectores ya que reconoce en ellos la facultad de una visión crítica, reflexiva y profunda sobre la vida.

Los autores contemporáneos hablan de la muerte a partir de la belleza, por ejemplo, en Mi amigo el pintor (1986); o de la frustración, en El cochinito de Carlota (1996), pero sin generar ideas que intimiden o engañen a los pequeños, y les permiten un amplio rango de interpretación pues su función no es eminentemente didáctica. La Literatura Infantil contemporánea no da recetas para aprender a vivir la vida, ni marca un camino axiológico en el desarrollo de los pequeños; crea una ficción a la que es invitado el niño para conmoverlo y retarlo a que reflexione, de modo que sea capaz de configurar un punto de vista a partir de la gestación de ideas propias.

\section{Caracterización de la Literatura Juvenil}

A pesar de que se ha acuñado el concepto "Literatura Infantil y Juvenil" en un acrónimo brevísimo, para su simplificación: LIJ, es indudable que los públicos a los que estas obras se dirigen son muy diferentes; tal vez lo único que estos grupos tengan en común es su no pertenencia al grupo de adultos. Parece necesario, entonces, hacer un esbozo para caracterizar de manera particular la Literatura Juvenil, o consumida por jóvenes (no niños y no adultos), y observar cómo hemos propuesto acercamientos teóricos y críticos al respecto. Cabe señalar que las líneas divisorias entre la Literatura infantil, juvenil y adulta no responden a una clasificación etaria, necesariamente, ni son claras sus fronteras, pues una novela como Los mil años de Pepe Corcueña (2010), de Toño Malpica, de acuerdo con la clasificación de El Naranjo, está dirigida a jóvenes lectores (sin considerar su edad biológica), pero es disfrutable y comprensible para lectores iniciales (si se les lee en voz alta), pero sobre todo para el adulto lector, es decir, con experiencia literaria. En términos artísticos, entonces, es muy complejo definir las características específicas de la Literatura Juvenil que además no corresponden directamente a la literatura comercial conocida en la tradición anglosajona con la etiqueta Young Adult.

La tendencia popularizada en los años ochenta de escribir historias especialmente para jóvenes, con diferentes niveles de moralización sobre temas sociales considerados tabú para la época, empezó a clasificarse como Literatura para adultos jóvenes, por lo que se asumió ese concepto equivalente a Literatura Juvenil, o incluso al modelo Bildungsroman del romanticismo europeo; sin embargo, es una confusión muy similar a la que se genera 
cuando nos referimos a cultura $p \circ p$ y cultura popular. En el primer caso, el adjetivo $p o p$, empleado para explicar la cultura mediática, norteamericana particularmente, alude al consumo de masas y a la manipulación que de las expresiones culturales realizan los medios de comunicación; el segundo, se refiere a las prácticas culturales emanadas de las culturas populares: tradicionales, híbridas, de los pueblos originarios, arraigadas fuertemente en sus prácticas ancestrales.

La literatura Young Adult presenta, de manera muy general, temas polémicos desde una perspectiva sensacionalista y reduccionista para generar morbo y simplificación de la enseñanza moral. En esta corriente podríamos agrupar novelas como Nacida inocente (1974) o, en nuestro contexto, Juventud en éxtasis (1993). Son propuestas textuales que parten de un gran aparato publicitario enfocado al consumo masivo de sus productos. Por otra parte, de esencia muy diferente, encontramos la Literatura Juvenil contemporánea, creada con los mismos paradigmas de la Literatura sin adjetivos: es polisémica, lúdica, retadora, divertida; totalmente alejada de los dogmas, la condescendencia y la trampa de la moralización.

En este sentido, definir qué obras deberían considerarse como parte de este corpus por su valor literario es un asunto complejo que los críticos tendrían que asumir; sin embargo, no podemos soslayar que los paradigmas para establecer un canon son impuestos por grupos de poder que, a partir de sus funciones en el sistema de producción, legitiman diferentes prácticas sociales. En este proceso de legitimación y reconocimiento de los productos culturales se establecen criterios de evaluación orientados a dar vigencia a distintas manifestaciones artísticas. Es decir, el crítico, necesita una visión profunda sobre el fenómeno lingüístico y literario.

La Literatura en Occidente no ha sido ajena a esta validación por medio de diferentes prácticas, dentro de las que destacan la producción y reproducción de los discursos desde la alta cultura, a través de los canales que suponen la difusión, distribución y comercialización de libros y autores, así como la discusión académica en torno a sus temas y productos. La Literatura Juvenil en México ha sido víctima de estas dos grandes omisiones: no se difunde apropiadamente (porque las editoriales prefieren dar visibilidad a productos comerciales más vendibles; porque en las escuelas seguimos prefiriendo la literatura "clásica", o apostamos por textos "literarios" que aporten algún tipo de "enseñanza" moral a los lectores, etcétera); y casi no se discute en espacios académicos formales (si acaso se hace en contextos pedagógicos y no literarios).

Las causas de este abandono pueden ser múltiples, pero una de las más probables es que, igual que la infantil, la Literatura juvenil es considerada como un subgénero que, por ser para "adultos incompletos" no tiene la seriedad propia del "nivel literario" canonizado. Lejos de creer que esta forma particular sea un subgénero o una manifestación embrionaria de la Literatura, hemos visto que, independientemente del éxito comercial y artístico de producciones creadas para este público, en el mundo anglosajón han tenido gran éxito obras y autores que escriben para el público juvenil, como la saga de Harry Potter (19972007), Los juegos del hambre (2008-2010) y Las crónicas de Narnia (1950-1956). Independientemente del mercado en inglés, estas obras suelen traducirse al español para estar al alcance de los hispanohablantes ya que el público joven, con peculiaridades evidentes, también estimula y exige la creación de sus propios universos. 
De acuerdo con Philippe Ariès y George Duby (2001), el concepto de juventud, como sector de población con rasgos propios, es resultado del desarrollo de las fuerzas productivas en Occidente, consecuencia de la necesidad de preparar a los individuos para su integración a la vida productiva y social de un grupo con características exclusivas. Por ello, la escuela y la vida escolar representan un espacio que acota los intereses y temáticas de estas comunidades, quienes establecen sus propios códigos y lenguajes para interactuar. La visión de la Literatura Juvenil contemporánea no está exenta de este enfoque, y se enmarca en la vida escolar; a su vez, integra a sus propuestas las nuevas realidades, como la virtualidad y la tecnología, tan distantes del mundo adulto tradicional. A eso, quizá, se deba el rechazo que muchos escritores y críticos literarios consagrados sienten por la Literatura Juvenil.

Por otra parte, la condición biológica del joven, que no es determinante en ningún sentido para clasificar el gusto literario, también determina la forma en que se procesa el texto literario, ya que la capacidad del adolescente para el desarrollo del pensamiento hipotético deductivo (Piaget e Inhelder, 2007) se dispara a partir de la complejidad que ofrecen planteamientos como los emanados de la Literatura. Es evidente que los textos infantiles y juveniles se perfilan, hasta cierto punto, de acuerdo con el estadio del desarrollo psicogenético de sus lectores.

La condición intelectual del joven presenta una serie de manifestaciones que rompen con la afabilidad del mundo infantil y lo conducen a la rebeldía natural contra lo establecido, y a la crítica profunda de su realidad, proceso que se alienta a través de sus lecturas. El adolescente está listo para generar nuevos vínculos y relaciones afectivas determinantes más allá de las familiares, y ello lo conduce a un estado en el que la búsqueda de la aceptación es primordial para afianzarse con cierta seguridad en el mundo. Según Ariès y Duby, cuando la estructura social hace posible los lazos directos entre los adolescentes, estos pueden desarrollar el sentimiento de una conciencia común (2001), de ahí la importancia que la Literatura tiene entre los jóvenes, puesto que les otorga la posibilidad de conocerse así mismos en el otro.

En este sentido, escribir y leer Literatura para jóvenes puede tejer la urdimbre para sostener relaciones afectivas entre diferentes usuarios de la cultura escrita. Asimismo, la función de un maestro, promotor o gestor cultural, lejos de ser prescriptiva, tendría que orientarse hacia la construcción de puentes que permitan que el lector integre su experiencia propia con la Literaria; y ello, a su vez, podría acercar a los adultos, de forma genuina, a los temas que interesan a los jóvenes actuales, ya que los autores contemporáneos hacen propuestas literarias lúdicas y complejas que apuestan por la integración de diversas habilidades cognitivas, sociales, lingüísticas y emotivas para su interpretación. Debido a esta función integradora del texto literario, las propuestas de la Literatura Juvenil aportan las condiciones para formar comunidades de lectura, a través del desarrollo de lazos afectivos entre lectores, libros, autores, etcétera, y con ello, la posibilidad de construir un mundo más solidario. Es por eso que la crítica literaria formal sobre Literatura Juvenil tiene un campo muy rico y complejo para trabajar.

En México podemos reconocer un interés particular por los asuntos juveniles desde la literatura de la Onda; en los últimos años, encontramos propuestas literarias totalmente frescas, donde autores como J. E. Pacheco, M. Baranda, A. Chimal, R. Chávez Castañeda o 
J. Villoro no se han detenido para adentrarse en el mundo de los adolescentes y jóvenes, pero además, otros autores contemporáneos, formados académicamente para ella, aportan una nueva dimensión a la Literatura Juvenil, como es el caso de los hermanos Malpica, J. A. Sandoval, A. Romero, M. Riva Palacio, R. Castro, M. Osorio Gumá, entre otros.

Estos autores no se amedrentan ante las realidades que rodean a los lectores jóvenes de hoy y plantean todo tipo de temas, sin obedecer a la antigua práctica editorial de la censura. Esta Literatura también es un planteamiento político que abona a la creación de Literatura compleja y estimulante para acompañar a lectores que aún no son considerados dentro del público adulto, pero también hace un llamado a la reflexión estética y crítica a los adultos de cualquier edad y a la competencia lectoliteraria en vías del desarrollo de su pensamiento crítico.

Es necesario enfatizar la propuesta teórica sobre los diferentes conceptos de posmodernidad en la Literatura para jóvenes y niños, así como de neosubversión elaborados por la investigadora Laura Guerrero Guadarrama quien, a través de su arduo trabajo en esta área, ha sido uno de los baluartes que sostienen la discusión académica sobre LIJ en nuestro país, y ha impulsado la construcción de espacios para la investigación desde las academias universitarias.

Al hacer sus indagaciones en torno a la posmodernidad dentro de la que se circunscribe la LIJ escrita en español, particularmente en España y México, Guerrero Guadarrama (2016) concluye que hay dos tendencias o enfoques, ocasionados por dos fuerzas en tensión: la neoconservadora y la neosubversiva. La primera consiste en regresar a las narrativas conservadoras; es decir, después de revelarse contra los patrones hegemónicos de los discursos moralizantes y pedagógicos empleados tradicionalmente en la Literatura Infantil, esta regresa al reconocimiento de la tradición y empieza a presentar obras que vuelven a despojar del elemento subversivo a las historias. Por otra parte, la subversión en la LIJ surge de la idea de que, a pesar de que la historia rompía con los esquemas tradicionales y la forma de tratar los temas, al final, la narración conducía a los protagonistas otra vez al orden establecido; es decir, se reintegraba al mundo cuestionado previamente, en muchos casos, de manera diferente, pero funcional. En la neosubversión, este retorno a la normalidad no sucede, por lo que sus propuestas no implican ninguna condescendencia ni red de protección para el lector (Guerrero Guadarrama, 2016, p. 14).

Las propuestas de la doctora Guerrero, en la Universidad Iberoamericana, sin duda, han sido cruciales para abrir espacios que nos permiten discutir en términos más profundos y complejos distintos fenómenos en la producción, circulación y recepción de la LIJ y también han apuntalado otros espacios de discusión en otras universidades mexicanas, como en las Facultades de Filosofía y Letras de la Universidad Nacional Autónoma de México (UNAM) y de la Universidad Autónoma de Nuevo León (UANL), la Universidad Veracruzana, a través de la Especialización en promoción de la lectura, o la Universidad de Chihuahua y el Colegio de San Luis, donde diferentes académicos hemos desarrollado proyectos de investigación, diplomados e impartido cursos profesionales sobre LIJ, fuera de sus espacios obligados, como lo era tradicionalmente la Literatura Infantil en las Escuelas Normales. Es importante reconocer que la doctora Guerrero ha formado críticos profesionales en el diplomado que coordina desde hace algunos años en la Universidad Iberoamericana, así como ha estimulado el diálogo alrededor de estos temas en la revista 
académica LIJ Ibero, especializada en la crítica, la divulgación y la creación de literatura para jóvenes y niños.

Asimismo, otras instituciones de nivel superior, como la Universidad del Claustro de Sor Juana, han consolidado la formación de escritores profesionales de LIJ a través de diferentes cursos y diplomados de profesionalización de la escritura creativa para niños y jóvenes; además, en otros recintos universitarios, como la Facultad de Filosofía y Letras de la UANL hemos podido integrar, desde 2017, el curso de Literatura Infantil y Juvenil en el currículo de la licenciatura en Letras Hispánicas, con resultados muy alentadores en cuanto a la formación de estudiantes con un interés genuino y visión crítica sobre este fenómeno, que es posible rastrear a través de sus publicaciones y ponencias en diferentes congresos sobre Didáctica de la Literatura. En este campo, es importante la labor de especialistas como Anel Pérez en la UNAM o Scherezade Bigdalí Hernández en la Universidad de Guanajuato para la formación de estudiantes que se han dado a la tarea de realizar eventos académicos para el diálogo y discusión de la LIJ, como las Jornadas Lijeras, con sede en la UNAM.

Por otra parte, en contextos semiformales, otros académicos, como Ricardo Chávez Castañeda, abonan a la Didáctica de la Literatura Infantil a través de cursos y talleres para diferentes públicos interesados en la creación formal de literatura, así como algunos escritores de ensayo están trabajando estos temas de manera sistemática, como Raquel Castro en La Jornada Aguascalientes, o el blog especializado en LIJ, Linternas y Bosques, de Adolfo Córdova, o la sección de Confabulario sobre LIJ en la que escribe Javier Munguía. Asimismo, la revista Navegantes, editada por Biblionautas y La Editorial Universitaria de la UANL, en Nuevo León, está abriendo un espacio para el diálogo a nivel académico como un punto de encuentro entre promotores, autores, maestros de literatura y otros agentes involucrados en la LIJ.

De igual manera, la organización y curaduría de las diferentes ferias especializadas como la FILIJ en Ciudad de México, con casi 40 años de tradición, o las recientes Ferias de Mérida y Oaxaca han consolidado la profesionalización y el acercamiento crítico a la producción literaria para jóvenes y niños. Algunas editoriales, como El Naranjo, se han distinguido por el cuidado editorial con que seleccionan y diseñan sus productos para niños como resultado del pronunciamiento, cada vez más contundente, de la crítica y la profesionalización de la mediación y la didáctica de la literatura para niños y jóvenes.

\section{Función de la crítica académica sobre LIJ}

Dentro de este panorama, se debe reconocer que la función de la crítica, tal como lo señala Eagleton (1999), es fundamental para estimular los procesos creativos entre los escritores de LIJ, así como consolidar los espacios para discutir, reconocer y valorar la obra literaria escrita para jóvenes y niños, de manera que se gesten, a través de la lectura literaria, lectores críticos y propositivos para enfrentar los problemas éticos, sociales y culturales que hoy nos circundan.

El texto literario trasciende la simple comunicación; establece un sistema de significaciones complejas, que necesariamente tienen que ver con disciplinas que, más allá de la 
obra en sí misma, aportan información sobre el emisor y su contexto (Greimas, 1976) que pueden ser más accesibles para el lector a través de la mirada del crítico.

Como hemos señalado, en la Literatura Infantil los recursos estilísticos se refuerzan a través de la imagen, y el sentido del texto se activa gracias a la información implícita que el lector tiene que completar. Por ello es importante descomponer, para su estudio, la obra literaria en la mayor cantidad de partes posibles; sin embargo, se deben vincular todos sus elementos, entre ellos y con la obra misma, para obtener un resultado unificador e integral del hecho literario. Es decir, una significación concreta (un mismo procedimiento, utilizado en contextos diferentes, adquiere una significación diferente) por lo que es importante saber identificar la obra según los ejes del lenguaje (comparables o paralelos) que pueden darse en relaciones de gradación, oposición, repetición, etcétera. En la obra en prosa este tipo de relaciones se da en dimensiones más vastas, pues allí se encuentran oposiciones de personajes, de situaciones, de topoi que dependen de la tradición literaria activa que, temporalmente, actúa como "código común" (Todorov, 1981).

La literatura infantil tiene sus propios recursos ya que, en el caso de los álbumes ilustrados, la ficción se apoya en la imagen; uno no es más relevante ni determina al otro, sino que debe ser entendido como una unidad cuyos códigos significativos son necesariamente ambos, pues cada una de las lecturas tiene información que debe ser decodificada para que exista el hecho semiótico (Barthes, 1971).

El último paso que debe establecerse en el análisis de la significación de la obra literaria, según Todorov (1981), es la reconstitución de su modelo; pues este da cuenta, en forma esquemática, de las relaciones estructurales existentes en el interior del texto y del modo en que se conectan. Esta noción de modelo se refiere a la disposición concreta de las diferentes relaciones pertenecientes al sistema; por consiguiente, habrá relaciones que, por no encontrarse a nivel de la obra, no pertenezcan al modelo (Todorov, 1981).

De acuerdo con Greimas, todo discurso relata una serie de hechos inscritos en un sistema de coordenadas espacio temporales (1976). Este aspecto es muy importante en la Literatura Infantil porque con los niños se aplica el dicho: "de la vista nace el amor", lo cual da relevancia al formato. Y por ello, importa el tamaño de los libros, el tipo de papel en el que esté impreso, la disposición de los elementos de la composición, etcétera; por lo tanto, en el álbum infantil ilustrado se establece una relación simbiótica indivisible.

En este mismo sentido, un análisis profundo y sistematizado de los temas, estructuras, entramado, caracterización y configuración de los actantes y personajes (Greimas, 1976) debe servirnos como una guía que rete y estimule a los creadores y también como una especie de cartografía por la cual se puedan reconocer las particularidades que hacen de un texto para niños o jóvenes el material idóneo que lo acompañe y lo ayude a hacerse preguntas sobre el mundo, para activar los diferentes niveles del pensamiento crítico.

Es urgente que la visión crítica cuestione las fórmulas y formatos en que las editoriales ofrecen material de lectura para niños que, en algunos casos, sirven a la domesticación de la personalidad de los lectores en ciernes y a la legitimación de un sistema cultural que, probablemente, ya resulta anacrónico para los diferentes contextos globalizadores en que se desenvuelven los ciudadanos potenciales del siglo XXI; por ello, es crucial revisar con detalle la selección y validez que realizan actualmente las editoriales comerciales que publican en español como respuesta a las propuestas neosubversivas de la LIJ. 
Finalmente, es fundamental reconocer que hoy, en México, estamos trabajando desde muchos frentes para que se reconozca el peso que tiene la Literatura Infantil y Juvenil, y la generación de prácticas culturales, dentro de las que destacan los efectos del consumo y la función de los medios, tanto en la oferta como en los procesos de mediación y recepción de la LIJ, no sólo en la formación de comunidades de lectores, también en la consolidación de la profesionalización en el acompañamiento crítico al público que aún no tiene tantas experiencias como las que pudiera tener un adulto.

\section{Referencias bibliográficas}

Ariès, P., y Duby. G. (2001). Historia de la vida privada II. Madrid: Taurus.

Arizpe, E., y Styles. M. (2004). Lectura de imágenes. Los niños interpretan textos visuales. México: Fondo de Cultura Económica.

Barthes, R. (1971). Elementos de semiología. Madrid: Tiempo Contemporáneo. . (1986). El placer del texto. México: Paidós.

Consejo Nacional para la Cultura y las Artes (Conaculta). (2015). Encuesta nacional de lectura 2015. Disponible en: https://observatorio.librosmexico.mx/files/encuesta_nacional_2015.pdf

Croce, B. (1997). Estética como ciencia de la expresión y lingüística. Málaga: Agora.

Eagleton, T. (1998). Una introducción a la teoría literaria. México: Fondo de Cultura Económica.

(1999). La función de la crítica literaria. Barcelona: Paidós Ibérica.

Flores Hilerio, D. (2014). Algunas características y funciones de la literatura infantil y juvenil mexicana contemporánea. Conferencia presentada en el Colóquio Internacional de Estudos Literários, en la Universidad de Mato Grosso, Brasil.

Gadamer, H. G. (1987). "Fundamentos para una teoría de la experiencia hermenéutica". En D. Rall. (ed). En busca del texto: teoría de la recepción, (pp. 19-29). México: UNAM. . (1998). El giro hermenéutico. Madrid: Cátedra.

González Gil, M. D. (1979). "Literatura infantil: necesidad de una caracterización y de una crítica literaria”. Cauce: Revista Internacional de Filología, Comunicación y sus Didácticas, (2), 275-300. Disponible en: https://cvc.cervantes.es/literatura/cauce/pdf/cauce02/ cauce_02_011.pdf

Greimas, A. J. (1976). Semántica Estructural. Madrid: Gredos.

Guerrero Guadarrama, L. (2012). La posmodernidad en la literatura infantil y juvenil. México: Universidad Iberoamericana. . (2016). Neosubversión en la LIJ contemporánea. Una aproximación a México y España. México: Textofilia-Universidad Iberoamericana.

Iser, W. (1987). El acto de leer: teoría del efecto estético. Madrid: Taurus.

Mendoza Fillola, A. (2004). La educación literaria. Bases para la formación de la competencia lecto-literaria. Málaga: Ediciones Aljibe.

Piaget, J. (1983). El lenguaje y el pensamiento en el niño. Buenos Aires: Editorial Guadalupe. Piaget, J. y Inhelder, B. (2007). Psicología del niño. Madrid: Ediciones Morata. 
Propp, V. (2006). Morfología del cuento. Madrid: Editorial Fundamentos.

Ramos, S. (1988). Filosofía de la vida artística. México: Espasa-Calpe.

Reyes, A. (1963). El Deslinde. Apuntes para la teoría literaria. México: Fondo de Cultura Económica.

. (1983). "Apolo o de la Literatura". En La experiencia literaria. Ensayos (vol. XIV) (pp. 82-99). México: Fondo de Cultura Económica.

. (1989). “Aristarco o de la crítica”. En J. L. Martínez. (Comp). El ensayo mexicano moderno (vol. 2) (pp. 298-312). México: Fondo de Cultura Económica.

Rosenblatt, L. M. (2002). La literatura como exploración. México: Fondo de Cultura Económica.

Sartre, J. P. (1991). ¿Qué es la literatura? Buenos Aires: Losada.

Todorov, T. (1981). Introduction to Poetics (vol. 1). Minneapolis: University of Minnesota Press.

Vygotsky, L. S. (1995). Pensamiento y lenguaje. España: Paidós.

. (2001). La imaginación y el arte en la infancia. México: Ediciones Coyoacán.

\begin{abstract}
This work presents a panoramic view of Children and Young Adult Literature developed in Mexico, in relation with the study in Academic field, and some editorial practices that have contributed to its dissemination and promotion, since in the last five years we have observed a transcendental evolution in the perception of some academic environments towards this literary manifestation. We approach this process from the modifications in certain academic programs of Arts in Mexico, as well as other specialized publications about Children and Young Adult Literature.
\end{abstract}

Keywords: Children's and Youth Literature - Specialized Criticism - Higher Education Mediation - Academics.

Resumo: Neste trabalho apresenta-se o atual panorama da LIJ no México em relação com a forma na qual tem sido introduzido seu estudo no âmbito acadêmico, e as práticas editoriais de algumas empresas que têm contribuído para sua difusão e promoção, já que nos últimos cinco anos temos observado uma evolução trascendental na percepção de alguns ambientes acadêmicos para essa manifestação literária. Abordamos esse processo desde as modificações em alguns programas acadêmicos das faculdades de Letras em México, particularmente da UANL assim como nas diversas publicações especializadas sobre a LIJ.

Palavras chave: Literatura infantil e juvenil - Crítica especializada - Ensino superior - Mediação - Academia.

[Las traducciones de los abstracts fueron supervisadas por el autor de cada artículo] 